\title{
103
}

\section{Evaluating issues and performance of a public transport network in a post-communist city using a quantitative spatial approach}

The urban dynamics in eastern Europe after the fall of communism (seen as a consequence of the changes generated by the transition to a new ideology) have highlighted deficiencies in local public services, including the public transport system. To identify and illustrate the shortcomings of a public transport system from this region, we analysed the transport network of Iaşi (Romania) by taking into consideration various dimensions of efficiency. Partial indicators were used as input for a geospatial analysis and to create complex indicators, which can be used both as tools to measure the performance of a public transport network and as instruments to evaluate the local administration and decision-makers. The results highlight the performance level of the transport network analysed, revealing a core-periphery structure (in the context of a polynucleated city) resulting from relics of the communist period. A GIS analysis was used to assess the efficiency of the public transport network in order to identify and visualise strengths and weaknesses in the local transport system.

Keywords: performance measurement, public transport assessment, geospatial analyses, clustering analysis, Iaşi 


\section{Introduction}

Since the 1990s, urban public transport systems in eastern Europe have received renewed attention, especially because mobility, production and distribution issues are interrelated in a complex and changing geographical setting (Rodrigue et al., 2006). According to a report by the International Association of Public Transport (UITP; see Internet 1), the urban public transport systems of eastern Europe countries face similar issues determined by poor capacity to adapt to the rapid changes in the urban environment resulting from the postcommunist transition. The demographic accumulation under the communist regime in eastern European cities was a result of forced industrialisation (Hirt, 2013) and increasing workforce demands (Light, 2001). Its impact on cities' internal dynamics was major (Sykora \& Bouzarovski, 2012; Tsenkova, 2014) and resulted in intensifying flows and relationships within the city (Young \& Kaczmarek, 2008). Dominic Stead et al. (2008) point out that the extension of the public transport system was a needed measure to serve the growing number of residents and increasing workforce flows. According to Ivan Tosics (2005), the collapse of communism in 1989-1990 brought about a totally new situation in which profound political and economic changes have become a subject of intense reorganisation of urban areas (Stanilov, 2007; Mavromatidis \& Mavromatidi, 2012). Alain Bertaud (2006) highlights that the main challenge was a shift from a monocentric pattern to a polynucleated city; thus, the original morphological shape went beyond the city's administrative limits, mainly caused by spill-overs (Couch et al., 2007; Stefanovska \& Koželj, 2012). The first to adapt to these new transformations were mostly medium-sized and large cities with an industrial profile, which experienced various issues such as gentrification (see also Tsietsi Monare et al., 2014) or higher internal dynamism generated by the new links established within and beyond their limits. The economic and political transformation also resulted in great changes in the transport of goods and people (Akimov \& Banister, 2011). John Pucher and Ralph Buehler (2005) state that the most obvious indicator of this change is the dramatic growth in private vehicle ownership and use, which has also contributed to the decline of public transport system use (Crass \& Short, 1996). This was also exacerbated by incoherent local planning strategies concerning the transport system, which could not adapt to the continuously changing city.

Nowadays, measuring and assessing the performance of a public transport network have become a rather common approach in transport geography. In contrast to most studies (Golob et al., 1972; Glover, 2011; d'Arcier, 2014), which focus on analysing various elements of the transport system - comprising transport infrastructure, vehicles, equipment, function- ality and management (Allsop, 2008), which form a set of complex relations between demand, the location served and the support networks (Rodrigue et al., 2006) - studies focusing on the transport network (Kasikitwiwat \& Chen, 2005; Lu \& Shi, 2007; de Cea \& Malbran, 2008; Chung et al., 2009; Ducruet \& Lugo, 2013; Salonen \& Toivonen, 2013) have a rather technical approach that is incomprehensible for decision-makers on the one hand, and on the other hand is limited to network analysis. Traditionally, transport networks are studied from a graph theory perspective (Roberts, 1993), which is a branch of mathematics proposing concepts and measures about the topology of networks considered as sets of nodes (vertices) connected by links (edges) (Ducruet \& Lugo, 2013). According to Marc Barthelemy (2010), from a publicutility point of view, a transport network is a realisation of a spatial network, representing a structure that permits vehicular movement or the flow of a commodity.

This article evaluates the local public transport network of Iaşi, Romania using GIS-based tools that assess the main features of an urban network, also taking into consideration elements of the transport system (urban fabric, population distribution) because local decision-makers have become aware of the relevance of research in order to adapt to a rapidly changing environment. Several objectives create a framework for determining whether an urban public transport network serves a city in a balanced manner. The first objective, based on a literature review, is to create a framework for various public transport measurements based on the data available. The second objective is to evaluate the current state of the public transport network using various indicators. The third objective is to determine the role of each public station in the urban network according to its proximity in the urban configuration. The study uses the urban public transport system of Iaşi as an example. Iaşi is a second-tier city (Parkinson et al., 2012) that shares similar development features with most eastern European urban settlements. Most studies focus on capital cities, which have a more complex transport system, and there are few analyses addressing second-tier cities (where many urban residents live). Therefore, this empirical study is representative and can be replicated for any eastern European city in this category, highlighting a post-communist system's capacity to adapt to urban changes.

\section{Theoretical background}

As Matthew Karlaftis and Dimitrios Tsamboulas (2012) point out, the literature on public transport systems is extensive. Analyses have focused both on developing methods for assessing system performance and on using findings to make different policy recommendations (Curtis \& James, 2004; Pucher \& 
Buehler, 2005; Goldman \& Gorham, 2006; Stead et al., 2008; Curtis et al., 2010; Camargo Pérez et al., 2015). According to Bruno Faivre d'Arcier (2014: 68), performance measurements can be classified into three categories:

- "productivity measures, focused on efficiency and effectiveness indicator (Sampaio et al., 2008; von Hirschhausen \& Cullmann, 2010; Curtis et al., 2010; Eboli \& Mazzulla, 2012; Karlaftis \& Tsamboulas, 2012; Mishra et al., 2012; Jarbouin et al., 2012; Sami et al., 2013; Ayadi \& Hammemi, 2013; d'Arcier, 2014; Georgiadis et al., 2014; Isabello et al., 2014);

- "quality measures - performance is perceived from the rider's perspective in terms of frequency, reliability, comfort, speed, safety and time distance (Eboli \& Mazzulla, 2012; Salonen \& Toivonen, 2013);

- "impact/availability measures that examine performance through indicators like accessibility to jobs or major activity centres for special-needs populations (Horak et al., 2014)."

Jeffrey R. Kenworthy (2006) states that public transport is one of the services that was not entirely able to adapt to a liveable city. Passenger transport in large- and medium-sized cities mainly relies on the transit system. Bin Yu et al. (2005) consider the economy of transit network planning to directly influence travel time, passenger transfer rate and overall operating costs. The effect of the free market together with the low quality of public transport generated a high demand for cars. Pucher and Buehler (2005) argue that these situations created a rollover effect: urban policymakers have to deal with the negative consequences (on urban planning, quality of life and urban environment) created by this situation (Hoxha et al., 2014). "Instead, strategic planning for public transport has often been unambitious, with most proposals offering incremental improvements to the existing radial, monocentric network based on demand forecasting rather than future planning in the context of meeting policy objectives" (Curtis \& Scheurer, 2012: 2). The intensity of using public transport services varies from city to city and it is directly determined by local administrative policies, residents' behaviour, morphological factors of settlements, and also competitiveness translated in terms of speed, price, access and accessibility (Lei \& Church, 2010) or connectivity to the network. Matthew Karlaftis and Patrick McCarthy (1997) identified a threefold approach to public transport systems in urban areas: quality, efficacy and efficiency.

Assessing the quality of a public transport system is based on 1) passengers' views of various attributes (frequency, price, vehicle characteristics, travel time, etc.), which create a general perception of the quality of services supplied (Verovšek et al., 2013), and 2) the operators that provide these services (Dragu et al.,
2013). Breno Ramos Sampaio et al. (2008) relate efficacy to the number of users of public transport in relation to population, to the kilometres of routes provided and to the satisfaction level, all included in high-quality service for the lowest fare possible. Efficacy is one of the principles that guides the management of a public/private transport operator in cities in eastern Europe. Therefore, investments are oriented to acquiring high efficacy instead of high quality, resulting in a discrepancy between passengers' expectations and the services provided. "Efficiency has long been a critical consideration in both policy and operational decisions of public transport operators, and public transport efficiency has recently become even more vital" (Barnum et al., 2011: 1160). The three aspects mentioned above create the premises for analysing the performance of a transport network. In order to evaluate it, researchers use different methods according to the data available and the aspects that are supposed to be highlighted. Many studies use multicriteria analysis for various purposes. Most studies focus on identifying the features of an individual public transport network (de Cea \& Malbran, 2008), but there are also studies that apply these methods to different networks (Lu \& Shi, 2007; Von Ferber et al., 2009; Scheurer et al., 2011; Karlaftis \& Tsamboulas, 2012) to compare the results. Of particular interest for this article are studies that approach multicriteria analysis in a different manner, using factorial analysis (Karlaftis \& $\mathrm{McCa}$ rthy, 1997), Spatial Network Analysis for Multimodal Urban Transport Systems (SNAMUTS; Curtis et al., 2010; Scheurer et al., 2011; Curtis et al., 2012; Curtis \& Scheurer, 2012) and Data Envelopment Analysis (DEA; von Hirschhausen \& Cullmann, 2010; Ayadi \& Hammemi, 2013). The literature provides a wider variety of methods, but these are the most appropriate for the aim and objectives of this study.

One method used to evaluate the performance of a public transport system is DEA. DEA is a measure of the overall efficiency that uses two different approaches: an "input-oriented measure of technical efficiency of public transport network and output oriented to judge their effectiveness" (Ayadi \& Hammemi, 2013: 245). Several studies based on this method have been conducted to assess the overall performance of a public transport system and hence the correlation between efficiency and effectiveness (Fielding et al., 1985; Chu et al., 1992; Viton, 1997; Husain et al., 2000; Karlaftis, 2004). Other authors purpose a network analysis based on a graph theory approach (Sienkiewicz \& Hołyst, 2005) as a method for analysing the performance of public transport (Knoppers \& Muller, 1995). "Graphs more or less connected are determined from two invariants such as node and line connectivity" (Mishra et al., 2012: 3). These studies usually focus on concepts such as centrality (Crucitti et al., 2006 ; Strano et al., 2007), nodality, connectivity and accessibility. Sabyasachee Mishra et al. (2012) have developed a single connectivity index for 
node, line, transfer centre and region accessibility in order to determine the performance of large-scale multimodal transit networks. The index comprises connectivity features and measures of accessibility, such as speed, capacity, frequency, distance to destination, activity density of the location and degree centrality.

Accessibility measures are often used as performance indicators for assessing the equity dimension of public transport. Itzhak Beneson et al. (2011) consider the most commonly used methods to be location-based measures, which provide insight into the accessibility of locations. For this purpose, policymakers and researchers have developed various instruments according to data availability, land-use and a city's urban morphology for instance, Public Transport Accessibility Levels (PTAL) in Greater London, Greater Manchester Accessibility Levels (GMAL) in Greater Manchester and Urban.Access in Tel Aviv. The "Spatial Network Analysis for Multimodal Urban Transport Systems (SNAMUTS) accessibility instrument represents a GIS-based tool to assess the relationship between public transport network configuration, performance and service standard and the geographical distribution of land use activities across a city" (Internet 2). SNAMUTS uses a set of indicators that are analysed for further planning-support tools, strategic land use and transport planning. The SNAMUTS research team is led by Carey Curtis and Jan Scheurer, two specialists that applied their previous theoretical research in several projects in which they used different (Alexander \& Hedgcock, 2010) models for more efficient and sustainable public transport.

\section{Materials and methods}

To evaluate public transport network issues, several data sources were put together to create a basis for geospatial analysis and, implicitly, to obtain the final output of this study.

\subsection{Study area}

Our analysis takes into consideration the built-up area of Iași and the suburban localities connected with the city through public transport. Iași, located in eastern Romania, is the fourth-largest city in the country with a population of approximately 263,410 (Internet 3 ). Iaşi faces a post-communist transition (like all major cities on the eastern border of the EU), being shaped by hallmarks of the urban environment induced by policymakers of the last fifty years. As a consequence, most of the residents $(50 \%)$ are concentrated in the western districts of the city, which served as collective residences for people working in the industrialised district (on the eastern side of
Iaşi). The remaining districts have a diverse and heterogeneous functionality characterised by the presence of the regional and national functions (educational, medical, cultural, administrative, etc.).

Nowadays, the city is passing through a period of urban rehabilitation; the main changes are seen on the fringes of the city, where the new industry and the retail economy are located, and in the central part of the city, where quaternary services (especially the IT industry and advanced producer services) are concentrated. The city's further economic growth relies on these functions and the city is the main growth pole that influences not only Romanias North East Region but also has effects beyond the eastern border of the EU. Nevertheless, the local public administration still needs to adapt its strategies and views to a more dynamic and challenging free-market environment.

\subsection{Database}

The database used for computing public-transport issues in Iaşi uses the following datasets:

- Road network dataset (provided by OpenStreetMap 2014);

- One hundred thirty-eight public transport stations (obtained from the Autonomous Public Transport Operator of Iași [Rom. Regia Autonomă de Transport Public, RATP Iași );

- Public transport network (obtained from RATP Iași);

- Intensity of services (according to the RATP Iași timetable);

- Population at a detailed level (University Centre for Human Geography and Land Planning, Innovative Territories, Regional Management and Spatial Interaction: Cuguat TIGRIS).

\subsection{Geospatial analysis}

The database was analysed using various indicators based on spatial geometries (points and network); each of these reveals the individual and overall features either for each public transport station or for the entire network. Catchment area refers to the number of residents within walking distance $(400 \mathrm{~m})$ for each transport station as a percentage of the total potential population that can reach the station analysed. It was calculated using the Closest Facility tool from Network Analyst Extension in ArcGIS 10.1 software.

$$
C_{a(i)}=p o p C_{a(i)} * 100 / \text { pop }_{(i)}
$$


where:

$$
\begin{aligned}
& \mathrm{Ca}=\text { catchment area }(\%) \\
& \text { pop } C a(i)=\text { population within } 10 \text { minutes }(400 \mathrm{~m}) \text { travel } \\
& \text { time to station } i \\
& p o p(i)=\text { total population of station } i
\end{aligned}
$$

Closeness centrality is based on the length of the average shortest path between a station and all other stations of the network. The indicator measures how close or far a station is related to all others. It was calculated using the OD Cost Matrix tool from Network Analyst Extension in ArcGIS 10.1 software.

$C_{c(i)}=\left[\sum_{j=1}^{N} d(i, j)\right] /(N-1)$

where:

$C c=$ closeness centrality

$d(i, j)=$ total distance from station $i$ to station $j$

$N=$ number of all stations in the network

Betweenness of a station is defined as the ratio of shortest paths between pairs of other stations in the network that pass by that station (Freeman, 1977). It was calculated using Urban Network Analyst Extension in ArcGIS 10.1 software.

$$
C_{B(i)}=\sum_{j<k} P_{j k}(i) /(N-1)(N-2)
$$

where

$C_{B(i)}=$ betweenness centrality for station $i$

$P j k(i)=$ paths between stations $j$ and $k$ that pass through station $i$ for all $j, k \in N$ and $j \neq k$

$N=$ all stations in the network.

The betweenness measure is typically used to estimate the potential of passers-by at different stations on the network (Sevtsuk et al., 2011).

Degree centrality is defined as the proportion of stations directly connected to the station in question out of the total stations in the network. It measures the percentage of other stations that can be reached with a transfer-free trip (Scheurer et al., 2011). It was calculated using formulas in Microsoft Excel and then added to GIS database.

$$
C_{D^{(i)}}=\sum a^{(i j)} / N-1
$$

where:

$C D(i)=$ degree centrality of station $i$

$a(i j)=$ number of reachable stations along a path

$N=$ all stations in the network.
Nodal connectivity measures the strength of each station for integration of services. It captures the suitability of stations for making transfers or breaks of journey with minimum disruption to the flow of movement. It was calculated using formulas in Microsoft Excel and then added to GIS database.

$N_{C(i)}=\left(\sum\left(a_{i j}-2\right)\right) * N_{(i)} * F_{(i)}$

where:

$N c(i)=$ nodal connectivity index for station $i$

$a(i j)=$ links converging in station $i$ with $j \in N(i)$ and $i \neq j$

$N(i)=$ stations adjacent (nearest neighbours) to station $i$

$F(i)=$ number of public transport vehicles departures per hour per direction from station $i$

Service intensity indicates the total number of public vehicles passing through a station during rush hour. The demographic pressure of public transport vehicles highlights the pressure of possible users within walking distance $(400 \mathrm{~m})$ on public transport services. All values of the indicators described above were normalised to a scale from 1 to 10 , thus generating a global view of the issues of the public transport network. These were integrated into two complex indicators:

- A composite index (an adaptation from the SNAMUTS model) measures the performance of each station and was built by summing up six of the aforementioned indicators (degree centrality, closeness centrality, betweenness centrality, nodal connectivity, catchment area, intensity of services), which were converted to a scale from 1 to 10 to give them roughly equal weighting (Romanian $\mathrm{Na}$ tional Institute of Statistics).

- Using HAC (hierarchical ascendant classification), the stations were clustered into four categories according to the functionality of the built up area. HAC provides a better focus on the performance of each station.

\section{Results}

\subsection{General overview of the public transport network in lași}

The public transport network had multiple phases of evolution: from a radial structure (before the First World War) to a radial-nucleic one (the post-war period) and a polynucleated one today (Stoleriu, 2008). The network was especially designed to serve the growing demands of the industrial area materialised as heavy workforce flows (Figure 1). The changes the network faced during recent decades are quite minor and did not take into consideration the demographic desaturation of the city centre towards the peripheries and the growth of general mobility. 


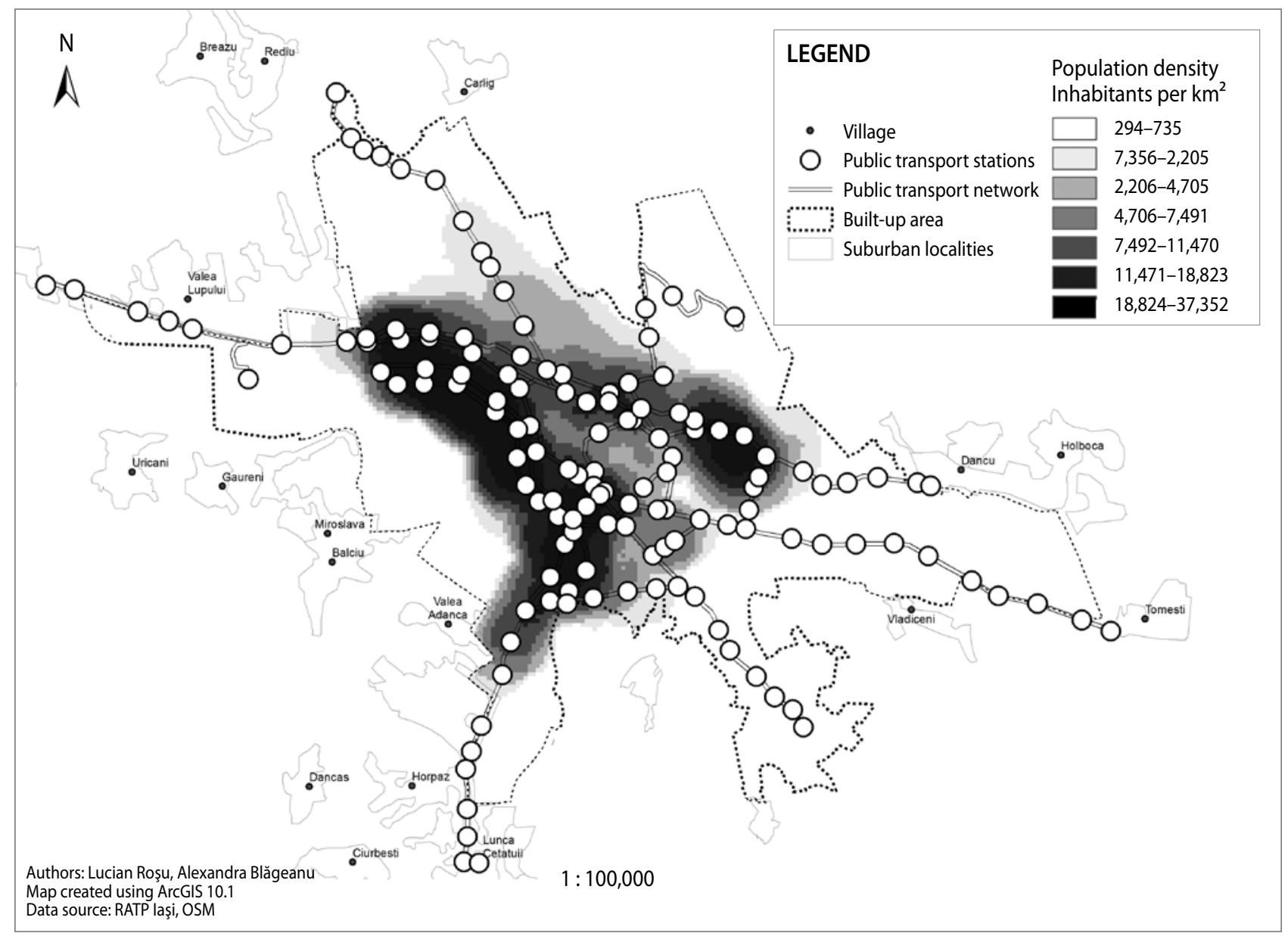

Figure 1: Public transport network in lași in 2014.

Table 1: Means of transport in lași in 2014.

\begin{tabular}{lll}
\hline No. & Means of transport & Number of routes \\
\hline 1 & Tram & 6 \\
\hline 2 & Bus & 21 \\
\hline 3 & Maxi-taxi & 4 \\
\hline
\end{tabular}

Several private companies operate within the metropolitan area and link the city with its outskirts. The public transport network is available only within the city and uses various means of transport, totalling thirty-one different routes (Table 1). The intensity of services varies from one to six vehicles per hour in one direction during rush hours.

\subsection{Equity of public transport services?}

In order to highlight the coverage of service for public transport, catchment areas were calculated for each station (Figure 2). As a result of the strategic planning, the network was extended along major roads, leaving other peripheral areas unserved. The main feature of these outskirts is the change of
Table 2: Population according to the distance to the closest public transport station in lași in 2014.

\begin{tabular}{lll}
\hline Population & Distance $(\mathrm{m})$ to station & $\begin{array}{l}\text { Percentage of total } \\
\text { population (\%) }\end{array}$ \\
\hline 8,186 & 50 & 2.5 \\
\hline 25,385 & 100 & 7 \\
\hline 97,286 & 200 & 26 \\
\hline 278,000 & 400 & 75 \\
\hline 357,000 & 800 & 96 \\
\hline 371,000 & 1,500 & 100 \\
\hline
\end{tabular}

profile (from rural to urban) and preservation of initial morphology features (individual residences: S-E, N-E or S-W). There still are some (highly populated) districts located at a distance greater than $400 \mathrm{~m}$.

Most residents (75\%) are located within walking distance (less than $400 \mathrm{~m}$; Table 2), but over 100,000 people (25\%) are located in areas beyond this threshold (more than $400 \mathrm{~m}$ ).

Most of the stations located inside the city capture more than $50 \%$ of the demand (catchment area), especially in high-den- 


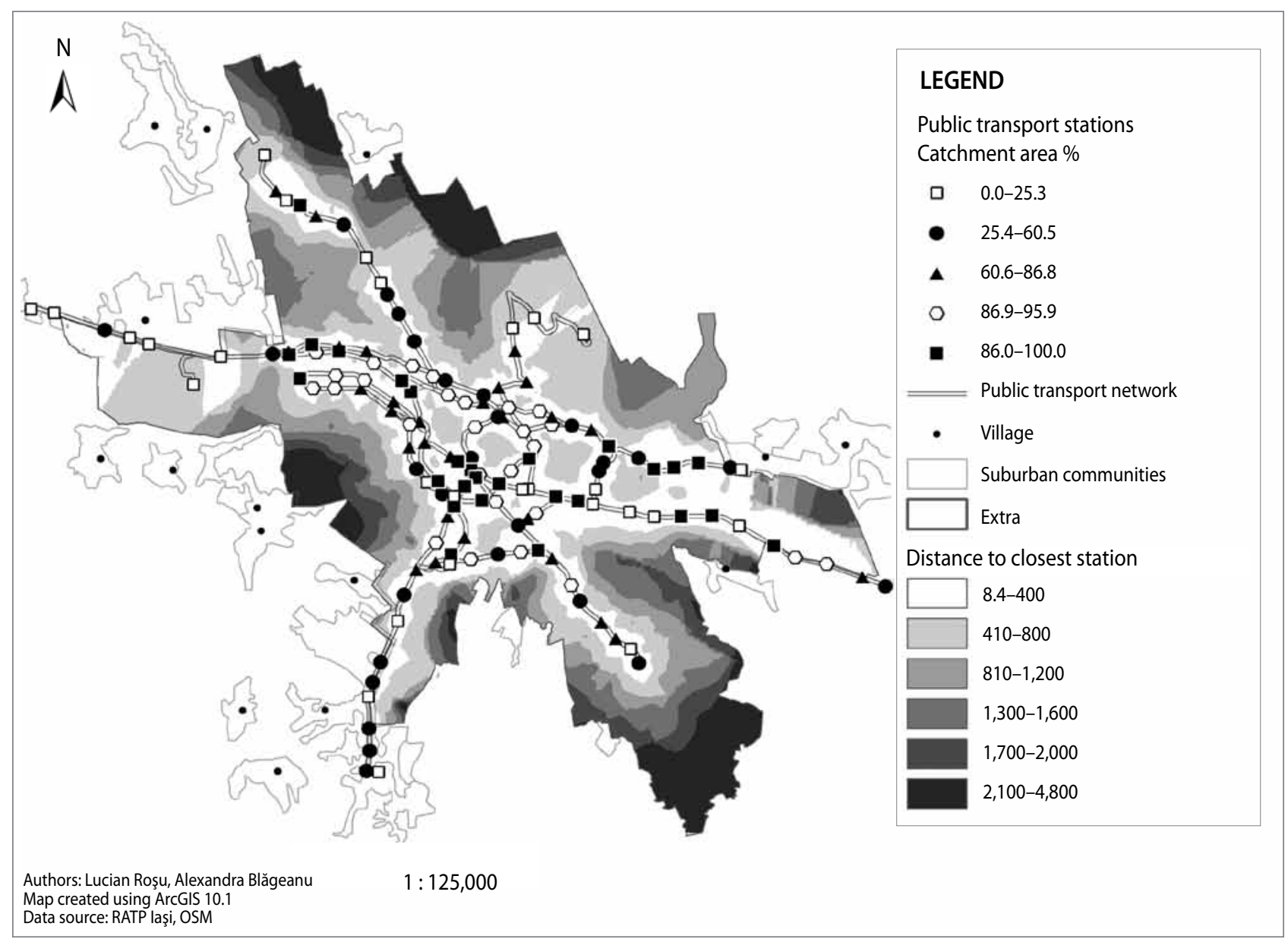

Figure 2: Catchment area in the lași public transport system in 2014.

sity districts ( $>90 \%$ of demand), showing their efficiency in meeting the needs of the work flows. The city centre is well served from this point of view, and most of the lines converge here. On the one hand, this area offers most facilities (jobs, recreation, culture, shopping, etc.), which could explain the current situation; on the other the hand, the high concentration of public transport vehicles creates traffic congestion. Terminus stations do not serve the demographic flows, but rather the facilities located there (shopping centres, the airport and industrial areas) and they also ensure a link between the city and its periurban localities (service is provided by private companies).

\subsection{Performance of the public transport network}

In order to evaluate the efficiency of public transport, a composite index was created. The global image of the public transport network (Figure 3) reveals the core-periphery logic of the planning system (retained from the communist period). Even though the suburban areas obtained relative independence and have become secondary nodes of the city (due to the presence of different services: commercial, economic and residential), access to them is quite minimal and is usually based on private vehicles. One of the negative effects of low performance of the public transport network at the edge of the city is the minimised interaction between the city and its fringe, determining a car-based profile for the socio-economic environment of the peripheral areas. At first glance, the builtup area of Iași has a good value of the composite index, highlighting the existence of a subsystem based on several transfer nodes that provide connections with all other parts of the city. However, the public transport system has preserved the relics of communist strategic policies; these elements can be observed in brownfields (where the stations have high values of the composite index; Figure 3).

The areas with high density and intensity of economic activities (overlaid on areas with an excellent composite index) are the result of a good connection with the entire city through the public transport lines. Theoretically, an efficient transport network should have a high intensity of services and a high connection with the entire city, which is not entirely proven in this case study. The districts on the western side of the city (where more than $50 \%$ of the total population lives) should have better values on the composite index, an aspect that denotes average connectivity and low intensity of services. Another 


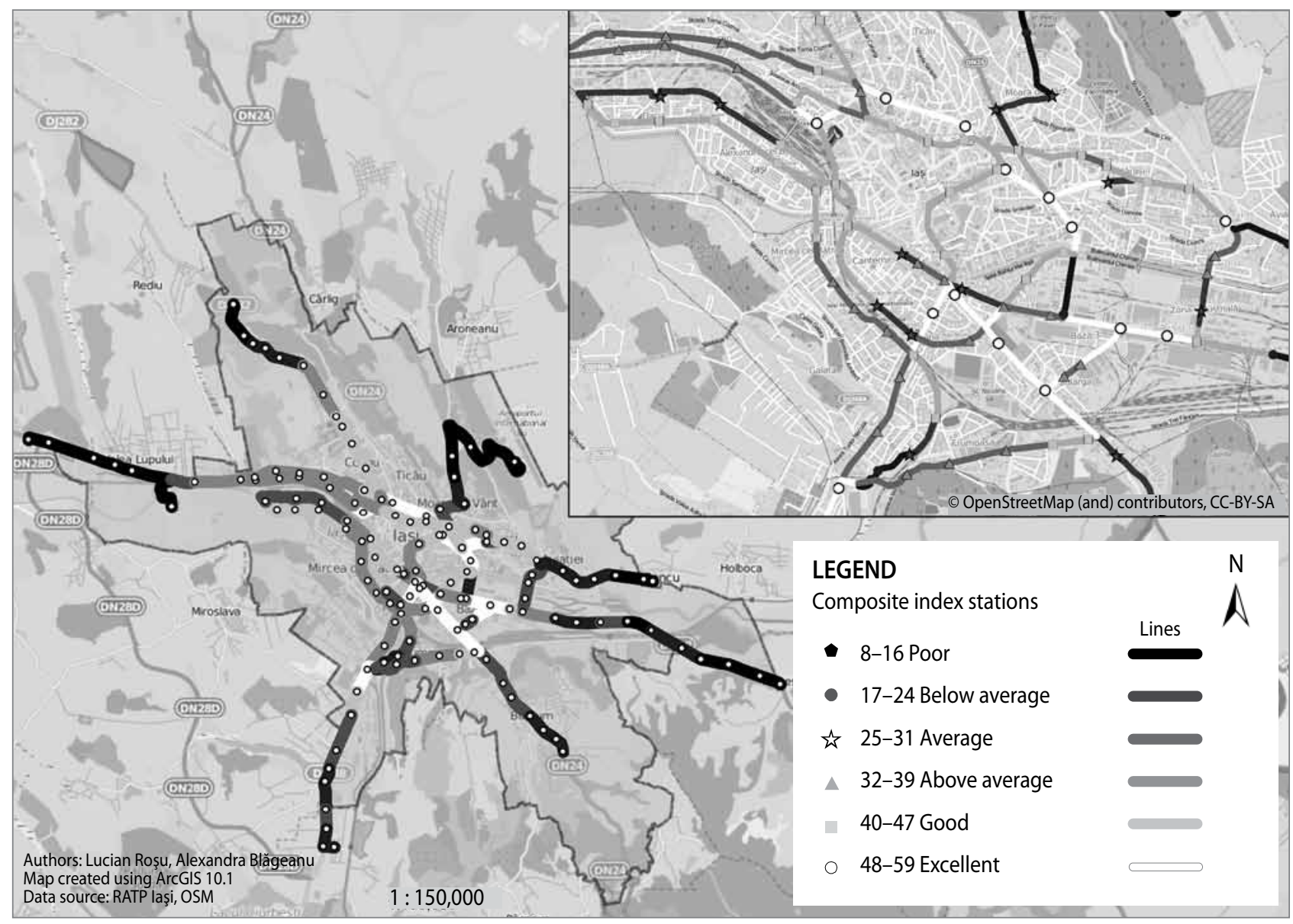

Figure 3: Composite index for transport public system of Iași in 2014.

aspect that is worth mentioning is the excellent connectivity of a district located on the eastern side of the city, even though it is known as a "grey-headed" neighbourhood (Stoleriu, 2008) with low mobility needs.

\subsection{Deficiencies of the public transport network using hierarchical ascendant classification}

The quality of the public transport network - in particular, deficiencies in meeting users' demands - was established using a cluster analysis. The stations were grouped into classes according to their shared characteristics regarding nine variables (functionality, service intensity, closeness centrality, betweenness centrality, nodal connectivity, degree centrality, catchment area, demographic pressure and demographic accumulation). The result is described below and displayed in Figure 4.

Class 1: The stations included in this group are in the densest neighbourhoods of the city; theoretically this implies that the values for each variable taken into consideration should be higher than average. For example, the intensity of services should be directly dependent on the demographic pressure, considering that these districts are the origin of the workforce flows represented by residents with a medium income, who are the main public transport users. The analysis shows values below average for five of the variables (service intensity, nodal connectivity, degree centrality, betweenness and closeness centrality) and reveals a limited role of the stations: they serve to transfer the population to other nodes of the network, but not to the entire city.

Class 2: This emphasises the peripheral areas of the city, characterised by long distances to central areas, low service intensity and low connectivity with the whole city. The stations can be found either in commercial areas (located at the fringe of the city) or in areas where industry and services dependent on large areas were relocated. On the other hand, their position does not meet the requirements of a higher demand that can create an increase in service frequency. The periurban residential areas are less dependent on the public transport network because the cost of travel by bus is almost the same as using a private vehicle (the case of carpooling or for an entire family).

Class 3: This class includes the main hubs of the network that the transport lines converge with; because of their key role in 


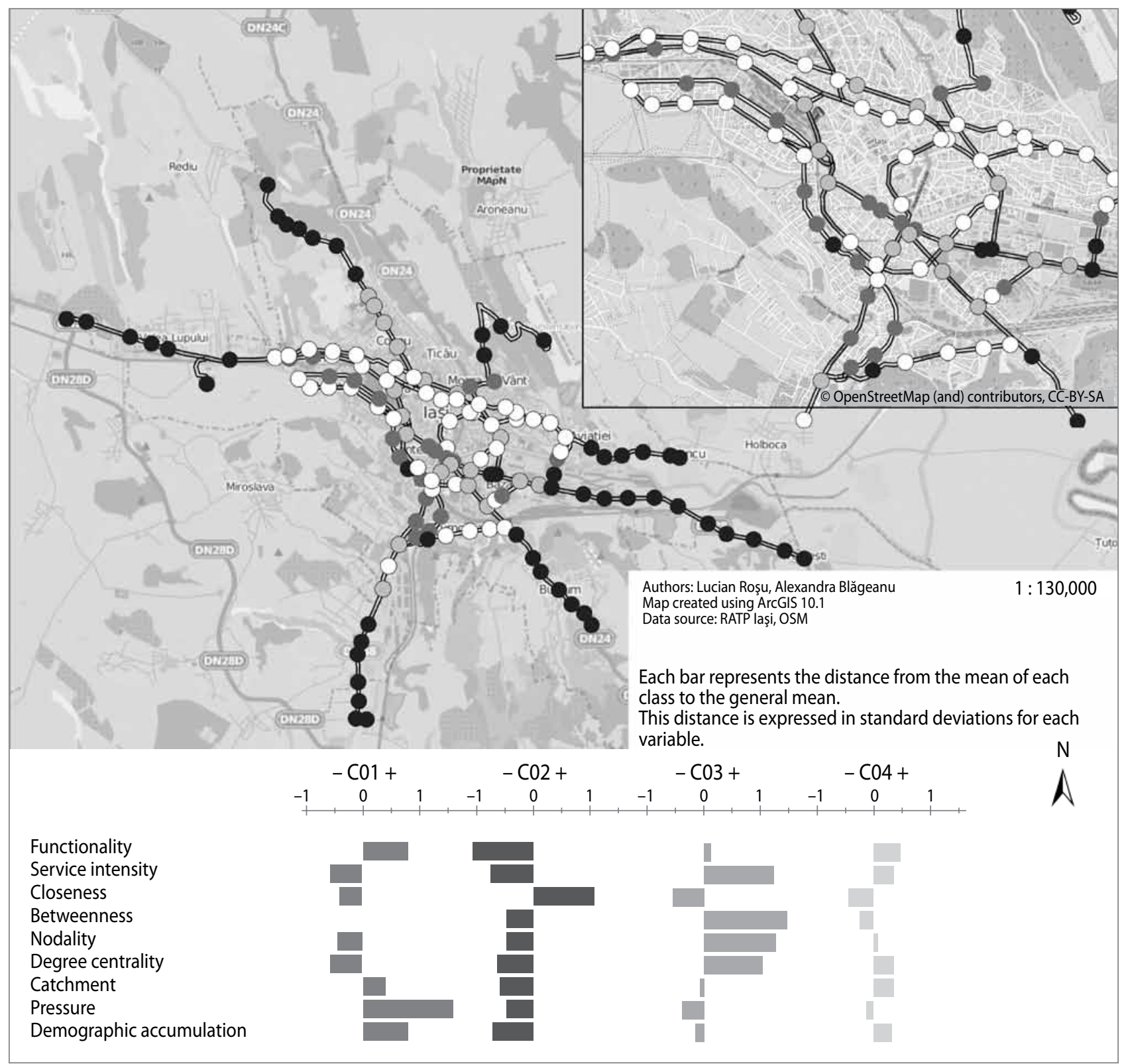

Figure 4: Hierarchical ascendant classification of public transport stations.

public transport networks, the furthest stations are more easily connected to them (Lu \& Shi, 2007). These are found in the most dynamic areas of the city (considering the agglomeration of services and economic performance), serving spaces with complex functionalities rather than residential areas (job concentration and educational, cultural and recreational areas). In some cases, this is the result of the decision-making process of the communist period. As the shape of the public transport network in Iaşi started to crystallise, the stations included in this class have played an important role in the system, serving areas with a rapid dynamic that are becoming the foundation for further economic impetus in the area. During the communist period, these were characterised by heavy industry (the central-south side of the city), transport nodes (a train station and bus terminals) and complex tertiary services (north- northwest). During the transition period, some of these areas have retained their functionality (north-northwest), but the industrial area has faced transformations, becoming a suitable playground for economies of agglomerations. They have a key position in the network, registering values high above average for four variables that were used in the cluster analysis (services intensity, betweenness centrality, nodality and degree centrality).

Class 4: The main difference the first class is the high service intensity, which reduces the demographic pressure on each station. These are located in neighbourhoods with a residential profile (high population density), which they used to connect with the old industrial areas of the city; they are relics that today retain their features as a result of the shortcomings of 


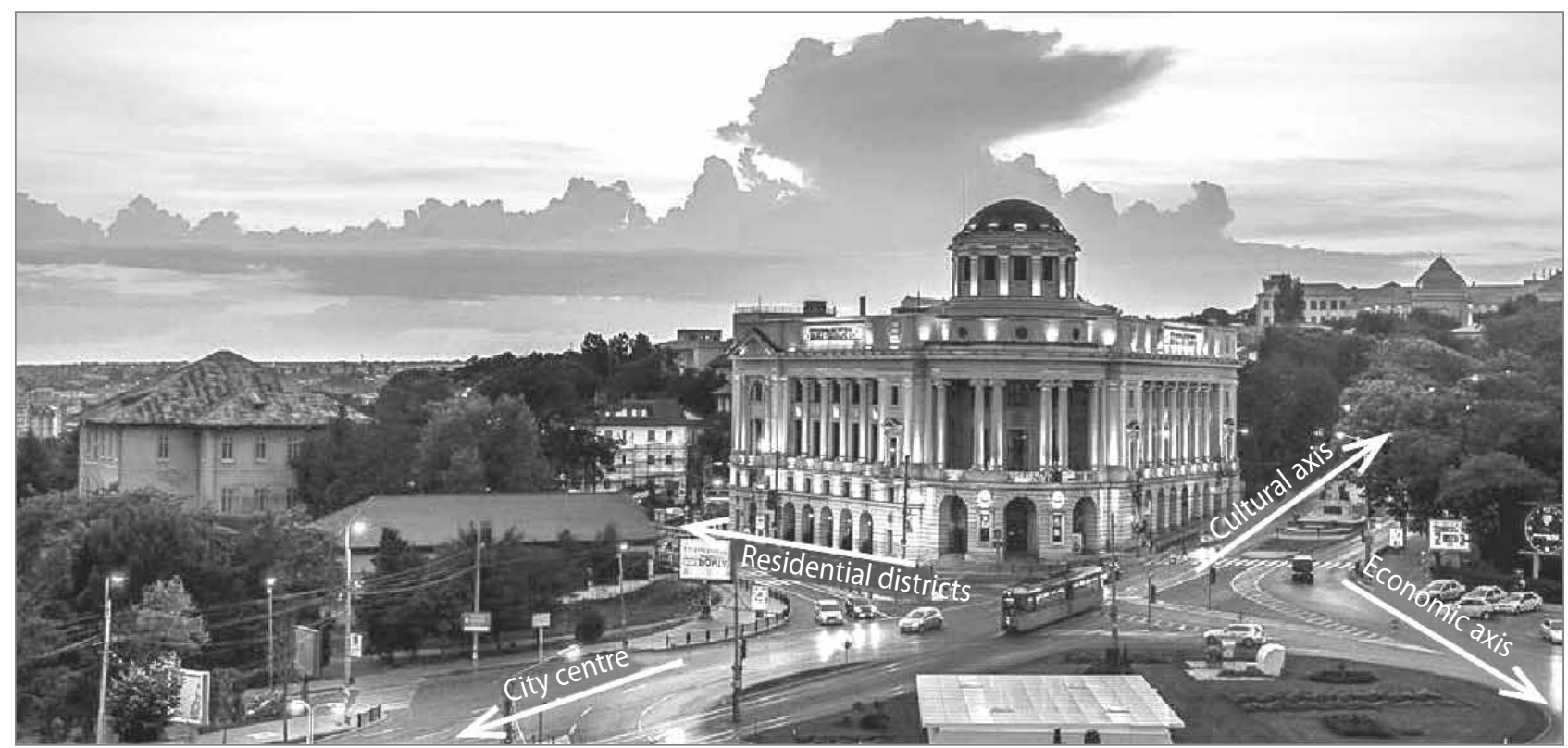

Figure 5: Urban public transport intersection in central lași (photo: Mihai Bulai).

reshaping the public transport network infrastructure. It is the class that interacts most with the residents. The values of most variables are close to average, being the most suitable for future inclusion in other classes (either by improving or decreasing the values). Therefore designing smart management for the public transport system could include some of the following measures: a differentiated frequency according to the demands of the population, readjusting lines towards the most dynamic areas, linking peripheral neighbourhoods between them and increasing the number of buses available, which could create greater efficiency.

\section{Discussion}

The shift from communism to a free market economy encouraged greater residential internal mobility, which could not be sustained by the public transport network. The changes in the transport infrastructure were rather insignificant (covering only parts of the existing network), being unrelated to the expansion of the built-up area due the lack of coherent strategies on the one hand and, on the other hand, to the chaotic development of peripheral areas. Regarding the service area coverage, three out of four residents are within a tenminute walking distance from the nearest station, which is a ratio higher than most of the scores obtained by European capitals (Scheurer, 2013). This value is explained by the concentration of population in communist-era districts (located in the periphery), which are served well by the transport services. The current development trends of the city are characterised by population movement and relocation of economic activities towards the periphery, and these trends should be supported by extending the public transport network.
The urban transport network is structured around the main radial development axes of the city, which are accompanied by a number of lines converging at its centre and other smaller lines that serve the more sparsely populated outskirts. From a topological point of view, the transport network has a monocentric structure that favours the maximisation of imbalances and congestion effects in the centre; as a consequence, the communist-era districts are not well connected with one another, and the residents are forced to cross the city centre in order to arrive to a desired location. The use of performance indicators highlights the existence or absence of systems within the major network, creating an image of the heterogeneity or homogeneity of the urban environment. The high scores are strongly related to the economic boost that emerged after the collapse of communism. It was transposed in territorial advantages, biasing higher competitiveness, agglomeration economies and generally a more dynamic setting. Karlaftis and Tsamboulas (2012) point out that for local decision-makers and urban stakeholders these features represent a degree of a system's progress in the process of remodelling the urban environment and achieving service and community objectives. Using hierarchical ascendant classification, one can identify the role each station plays within the urban transport network, with emphasis on issues that can lower the performance of the network. The method probes the possibility of improving the score of partial indicators, generating a positive effect on the entire network by creating the premises for developing new nodes.

The final outputs of this study can represent the basis for a further complex analysis that may be used to develop transportation strategies because they highlight issues in Iaşi's public transport network. Because the local administration 
has already drawn the limits of the metropolitan area of Iași, designing a single network that serves the entire territory in accordance with the shifts in land-use patterns appears to be mandatory. In order to better adapt to local conditions, the local decision-makers should take into account experts' advice to use models that estimate the efficiency of the public transport system. Curtis and Scheurer (2012) consider the re-evaluation of strategic planning issues to be one of the most important objectives that should take priority in local authorities' agendas in order to improve the quality of public transport. This should deliver better accessibility instead of mobility.

So far, not much attention has been given to the problem of improving public transport networks. In most eastern European cities, these networks have retained their communist features, which no longer fit users' needs. They are reflected in long travel times and a high number of transfers per trip, and are thus unable to cover the needs of a population with higher demands for mobility, generating traffic congestion inside the city and other related effects. Most studies addressed at decision-makers focus on western cities, where the needs for change are rather qualitative (improvements of speed, comfort, reliability, etc.), whereas post-communist cities are still facing network connectivity issues because of adjustment to a dynamic city. Christoph Mandl (1980) determined that the costs of rerouting public vehicles are low but can greatly improve the performance of a system in comparison to other investments for improving the service level of public transport systems. The applicability of the proposed methodological framework is dependent on available datasets, generating outputs with different complexity, thus imposing limitations on the present study; even though the analysis was conducted on a city with specific features regarding its size and form, the methods can be replicated (with some improvements) for other urban public transport networks. The final outputs are representative for local policymakers because they highlight a mismatch between the performance of the current public transport network and the growing needs of the city residents.

The method presented in this article for evaluating the performance of public transport is comparable with other methodologies provided by the literature - for example, SNAMUTS, which was the starting point in designing the study. This is one of the most complex models (and has been applied to twentysix major cities around the world) whose outputs can easily be used by policymakers and various stakeholders: investors, nongovernmental organisations, economists and designers (Pompe $\&$ Temeljotov Salaj, 2014). The indices that compose the model can be replaced according to data availability, making the model replicable at other scales. Other advantages (as well as our method) are provided by the refined level of analysis (it takes each station into consideration), the multitude of indexes (which can be used separately or as part of an indicator) and the flexibility of the composite indicator. Other studies (PTAL or GMAL) base their methodology only on accessibility issues, taking into consideration travel time, walking time and the number, level and reliability of services as a result of a highly developed transport system. This study primarily focuses on network analysis, addressing other specific issues, whereas accessibility measures are concentrated on population demands. The main difference between accessibility studies and network-based studies lies in the purpose of studies the former analyse equity in accessing the transport network, whereas the latter concentrate on identifying the issues for each element composing the transport network. On the other hand, the main shortcoming of the study is that the results are not easily to compare with other studies because the majority of previous researchers analysed a) city transport networks with different sizes and forms, b) metropolitan transport networks, which have different characteristics, c) transport networks that evolved in different historical contexts and d) urban transport networks with different methods and datasets. Some other disadvantages, such as not taking into consideration the functional zones of the city and accessibility measures, and the lack of certain variables (travel time, schedule or number of passengers), set the stage for future improvement of the model. "Obtaining some clarity, and making those measures readily understood by decision-makers, could go some way in raising the profile of accessibility modelling, and its importance in decision-making frameworks" (Curtis et al., 2010: 18). Achieving a balanced transport system will not be possible without integrating objective measures that point to the performance of the network system.

\section{Conclusion}

This paper applied quantitative methods (centrality and connectivity indexes) to a public transport network in order to evaluate the performance of this service. The public transport system in Iaşi is still characterised by elements that are relics from the communist period, even though it underwent some socio-economic changes (distinctive for a post-communist transition) over the last twenty-five years. In order to become more efficient, planning strategies should be more flexible and adaptable to the rapid changes that are occurring in an increasingly dynamic city. The transport stations serve almost $75 \%$ of the residents, but quite a large percentage of the population still deals with low accessibility. Thus, the actors responsible for transport policies should consider reorganising the current network so that the system becomes equitable by maximising coverage.

The individual analysis of each indicator can reveal individual deficiencies of the network. By putting them together, an over- 
all image of strengths and weaknesses is obtained. The composite index reveals the core-periphery character of the network system, even though the city has a rather polynucleated structure. Therefore the connectivity between different parts of the city is reduced, which negatively affects the cost and the length of journeys, causing both to increase. Stations with high nodality are located in areas characterised with complex activities (agglomeration of jobs and economic, cultural, educational and recreational services). The deficiencies of the network are pointed out by clustering the results of each indicator calculated; the types of stations according to their common features are also identified. Hierarchical ascendant analysis is therefore a method that makes it possible to highlight the following observations:

a. It creates a hierarchy based on a set of indicators;

b. It identifies the position and role of stations inside the local context (demand area);

c. It points out the position of public stations in the public transport network;

d. It determines the classes that are most sensitive to change with respect to public administration.

The application of the model developed in this paper could also be useful for "policy choices about public transport network design and service improvements as well as the integration of public transport routes and stations with the urban environment" (Scheurer et al., 2011: 21).

\section{Lucian-lonuț Roșu}

Alexandru loan Cuza University, Faculty of Geography and Geology, Department of Geography, lași, Romania

E-mail: lucianrosu@ymail.com

\section{Alexandra Blăgeanu}

Alexandru loan Cuza University, Faculty of Geography and Geology, Department of Geography, lași, Romania

E-mail: alexandrablageanu@gmail.com

\section{Acknowledgements}

This article was written and published under the aegis of the Research Institute for Quality of Life, Romanian Academy as a part of programme co-funded by the European Union within the Operational Sectorial Programme for Human Resources Development through the project for multidisciplinary and interdisciplinary doctoral and post-doctoral programmes, project code: POSDRU/159/1.5/S/141086.

\section{References}

Akimov, A. \& Banister D. (2011) Urban public transport in post-communist transition: The case of Tashkent, Uzbekistan. Comparative Economic Studies, 53(4), pp. 721-755. DOI: 10.1057/ces.2011.18

Alexander, I. \& Hedgcock, D. (2010) Planning perspectives from Western Australia: A reader in theory and practice. Bentley, W.A., Curtin University.
Allsop, R. E. (2008) Transport networks and their use: How real can modelling get? Philosophical Transactions of the Royal Society of London A: Mathematical, Physical and Engineering Sciences, 366(1872), pp. 18791892.

Ayadi, A. \& Hammemi, S. (2013) The evaluation of the effectiveness and efficiency of the public transport system in Tunisia: Application of data envelopment analysis, pp. 245-250. Paper presented at the International Conference on Advanced Logistics and Transport, 29-31 May, Sousse, Tunisia. Typescript. DOI: 10.1109/ICAdLT.2013.6568467

Barnum, D. T., Karlaftis, M. G. \& Tandon, S. (2011) Public transport versus private car: GIS-based estimation of accessibility applied to the Tel Aviv metropolitan area. The Annals of Regional Science, 47(3), pp. 499-515. DOI: 10.1007/s00168-010-0392-6

Barthelemy, M. (2011) Spatial networks. Physics Reports, 499(1), pp. 1-86. DOI: 10.1016/j.physrep.2010.11.002

Benenson, I., Martens, K., Rofe Y. \& Kwartler, A. (2011) Improving the efficiency of metropolitan area transit by joint analysis of its multiple providers. Transportation Research Part E: Logistics and Transportation Review, 47(6), pp. 1160-1176. DOI: 10.1016/j.tre.2011.04.006

Bertaud, A. (2006) The spatial structures of central and eastern European cities. In: Tsenkova, S. \& Nedović-Budić, Z. (eds.) The urban mosaic of post-socialist Europe, pp. 91-110. Heidelberg, Physica-Verlag HD. DOI: 10.1007/3-7908-1727-9-5

Camargo Pérez, J., Carrillo, M. H. \& Montoya-Torres, J. R. (2015) Multicriteria approaches for urban passenger transport systems: A literature review. Annals of Operations Research, 226(1), pp. 69-87. DOI: 10.1007/ s10479-014-1681-8

Chu, X., Fielding, G. J. \& Lamar, B. W. (1992) Measuring transit performance using data envelopment analysis. Transportation Research Part A: Policy and Practice, 26(3), pp. 223-230.

DOI: $10.1016 / 0965-8564(92) 90033-4$

Chung, M. C., Wei, C. H. \& Chen, C. J. (2009) Hierarchical evaluation scheme on technology sourcing for advanced public transport systems. Journal of Advanced Transportation, 43(1), pp. 89-111. DOI: 10.1002/atr.5670430106

Couch, C., Leontidou, L. \& Petschel-Held, G. (eds.) (2007) Urban sprawl in Europe. Oxford, UK, Blackwell Publishing Ltd. DOI: 10.1002/9780470692066

Crass, M. \& Short, J. (1996) Urban transport in eastern Europe. Organisation for Economic Cooperation and Development, The OECD Observer, 197(23), pp. 23-25.

Crucitti, P., Latora, V. \& Porta, S. (2006) Centrality measures in spatial networks of urban streets. Physical Review E, 73(3), pp. 1-4. DOI: 10.1103/PhysRevE.73.036125

Curtis, C. \& James, B. (2004) An institutional model for land use and transport integration. Urban Policy and Research, 22(3), pp. 277-297. DOI: $10.1080 / 0811114042000269308$

Curtis, C. \& Scheurer, J. (2012) Benchmarking public transport accessibility in Australasian cities, pp. 70-92. Paper presented at the 35th Australian Transport Research Forum, 26-29 September, Perth, Australia. Typescript.

Curtis, C., Scheurer, J. \& Burke, M. (2010) The dead end of demand modelling: Supplying a futures-based public transport plan. In: IImonen, M. \& Ache, P. (eds.) Space is luxury: Selected proceedings 24th AESOP annual conference, pp. 438-458. Espoo, Aalto University, Centre for Urban and Regional Studies Publications.

Curtis, C., Scheurer, J. \& Mallor, R. (2012) Spatial network analysis for multimodal urban transport systems. In: Hull, A., Silva, C. \& Bertolinini, 
L. (eds.) Accessibility instruments for planning practice, pp. 49-55. Brussels, COST Office.

d'Arcier, F. B. (2014) Measuring the performance of urban public transport in relation to public policy objectives. Research in Transportation Economics, 48(1), pp. 67-76. DOI: 10.1016/j.retrec.2014.09.033

De Cea, J. \& Malbran, R. H. (2008) Demand responsive urban public transport system design: Methodology and application. Transportation Research Part A: Policy and Practice, 42(7), pp. 951-972. DOI: 10.1016/j.tra.2007.12.008

Dragu, V., Roman, E. A. \& Roman, V. C. (2013) Quality assessment in urban public transport. Theoretical and Empirical Research in Urban Management, 8(3), pp. 32-43.

Ducruet, C. \& Lugo, I. (2013) Structure and dynamics of transportation networks: Models, methods and applications. In: Rodrigue, J. P., Notteboo, T. \& Shaw J. (eds.) The SAGE handbook of transport studies, pp. 347364. London, Sage Publication Ltd. DOI: 10.4135/9781446247655.n20

Eboli, L. \& Mazzulla, G. (2012) Performance indicators for an objective measure of public transport service quality. European Transport - Transporti Europei, 51(17), pp. 1-21.

Fielding, G. J., Babitsky, T. T. \& Brenner, M. E. (1985) Performance evaluation for bus transit. Transportation Research Part A: General, 19(1), pp. 73-82. DOI: 10.1016/0191-2607(85)90009-3

Freeman, L. (1977) A set of measures of centrality based on betweenness. Sociometry, 40(1), pp. 35-41. DOI: 10.2307/3033543

Georgiadis, G., Politis, I. \& Papaioannou, P. (2014) Measuring and improving the efficiency and effectiveness of bus public transport systems. Research in Transportation Economics, 48 (C), pp. 84-91. DOI: 10.1016/j.retrec.2014.09.035

Glover, L. (2011) Public transport as a common pool resource, pp. 1-15. Paper presented at the 34th Australian Transport Research Forum, 28-30 September, Adelaide, Australia. Typescript.

Goldman, T. \& Gorham, R. (2006) Sustainable urban transport: Four innovative directions. Technology in Society, 28(1), pp. 261-273. DOI: 10.1016/j.techsoc.2005.10.007

Golob, T. F., Canty, E. T., Gustafson, R. L. \& Vitt, J. E. (1972) An analysis of consumer preferences for a public transportation system. Transportation Research, 6(1), pp. 81-102. DOI: 10.1016/0041-1647(72)90113-X

Hirt, S. (2013) Whatever happened to the (post)socialist city? Cities, 32(S1), pp. S29-S38. DOI: 10.1016/j.cities.2013.04.010

Horak, J., Ivan, I., Fojtik, D. \& Burian, J. (2014) Large scale monitoring of public transport accessibility in the Czech Republic, pp. 157-163. Paper presented at the 15th International Carpathian Control Conference, 28-30 May, Velké Karlovice, Czech Republic. Typescript. DOI: $10.1109 /$ CarpathianCC.2014.6843589

Hoxha, V., Dimitrovska Andrews, K. \& Temeljotov Salaj, A. (2014) Cultural factors affecting urban planners' intentions to regulate public space in Prishtina, Kosovo. Urbani izziv, 25(2), pp. 76-89.

DOI: 10.5379/urbani-izziv-en-2014-25-02-001

Husain, N., Abdullah, M. \& Kuman, S. (2000) Evaluating public sector efficiency with data envelopment analysis (DEA): A case study in Road Transport Department, Selangor, Malaysia. Total Quality Management, 11(4-6), pp. 830-836. DOI: 10.1080/09544120050008282

Internet 1 http://www.uitp.org/sites/default (accessed 28 Apr. 2015).

Internet 2: http://www.snamuts.com/about-snamuts.html (accessed 27 Feb. 2015).

Internet 3: http://www.recensamantromania.ro/rezultate-2 (accessed 25 Feb. 2015).
Isabello, A., Pensa, S., Arnone, M. \& Rosa, A. (2014) Reviewing efficiency and effectiveness of interurban public transport services: A practical experience. Transportation Research Procedia, 1(1), pp. 243-252. DOI: 10.1016/j.trpro.2014.07.024

Jarboui, S., Forget, P. \& Boujelbene, Y. (2012) Public road transport efficiency: A literature review via the classification scheme. Public Transport, 4(2), pp. 101-128. DOl: 10.1007/s12469-012-0055-3

Karlaftis, M. G. (2004) A DEA approach for evaluating the efficiency and effectiveness of urban transit systems. European Journal of Operational Research, 152(2), pp. 354-364. DOI: 10.1016/S0377-2217(03)00029-8

Karlaftis, M. G. \& McCarthy, P. (1997) Subsidy and public transit performance: A factor analytic approach. Transportation, 24(3), pp. 253-270. DOI: 10.1023/A:1004956532174

Karlaftis, M. G. \& Tsamboulas, D. (2012) Efficiency measurement in public transport: Are findings specification sensitive? Transportation Research Part A: Policy and Practice, 46(2), pp. 392-402. DOI: 10.1016/j.tra.2011.10.005.

Kasikitwiwat, P. \& Chen, A. (2005) Analysis of transportation network capacity related to different system capacity concepts. Journal of the Eastern Asia Society for Transportation Studies, 6(1), pp. 1439-1454.

Kenworthy, J. R. (2006) The eco-city: Ten key transport and planning dimensions for sustainable city development. Environment and Urbanization, 18(1), pp. 67-85. DOI: 10.1177/0956247806063947

Knoppers, P. \& Muller, T. (1995) Optimized transfer opportunities in public transport. Transportation Science, 29(1), pp. 101-105. DOl: $10.1287 /$ trsc. 29.1.101

Lei, T. L. \& Church, R. L. (2010) Mapping transit-based access: Integrating GIS, routes and schedules. International Journal of Geographical Information Science, 24(2), pp. 283-304. DOI: 10.1080/13658810902835404

Light, D. (2001) "Facing the future": Tourism and identity-building in post-socialist Romania. Political Geography, 20(8), pp. 1053-1074. DOI: 10.1016/S0962-6298(01)00044-0

Lu, H. \& Shi, Y. (2007) Complexity of public transport networks. Tsinghua Science \& Technology, 12(2), pp. 204-213.

Mandl, C. E. (1980) Evaluation and optimization of urban public transportation networks. European Journal of Operational Research, 5(6), pp. 396-404. DOI: 10.1016/0377-2217(80)90126-5

Mavromatidis, L. E. \& Mavromatidi, A. (2012) Reinventing the doubt of the icon: A virtual case study in a post-Soviet country's capital. Urbani izziv, 23(2), pp. 79-92. DOI: 10.5379/urbani-izziv-en-2012-23-02-001

Mishra, S., Welch, T. F. \& Jha, M. K. (2012) Performance indicators for public transit connectivity in multi-modal transportation networks. Transportation Research Part A: Policy and Practice, 46(7), pp. 1066-1085. DOI: 10.1016/j.tra.2012.04.006

Parkinson, M., Meegan, R., Karecha, J., Evans, R., Jones, G. \& Sotarauta, M. (2012) Second-tier cities and territorial development in Europe: Performance, policies and prospects. Luxembourg, ESPON.

Pompe, A. \& Temeljotov Salaj, A. (2014) Qualitative criteria of urbanism and brands: A comparative analysis. Urbani izziv, 25(1), pp. 74-92. DOI: 10.5379/urban-izziv-en-2014-25-01-001

Pucher, J. \& Buehler, R. (2005) Transport policy in post-communist Europe. In: Hensher, D. A. \& Button, K. J (eds.) Handbook of transport strategies, policies and institutions, pp. 725-743. Oxford, Elsevier.

Roberts, F. S. (1993) Graph theory and its applications to problems of society. Philadelphia, Society for Industrial and Applied Mathematics. 
Rodrigue, J. P., Comtois, C. \& Slack, B. (2006) The geography of transport systems. London, Routlege.

Salonen, M. \& Toivonen, T. (2013) Modelling travel time in urban networks: Comparable measures for private car and public transport. Journal of Transport Geography, 31(1), pp. 143-153. DOI: 10.1016/j.jtrangeo.2013.06.011.

Sami, J., Pascal, F. \& Younes, B. (2013) Public road transport efficiency: A stochastic frontier analysis. Journal of Transportation Systems Engineering and Information Technology, 13(5), pp. 64-71.

DOI: 10.1016/S1570-6672(13)60123-3

Sampaio, B. R., Neto, O. L. \& Sampaio, Y. (2008) Efficiency analysis of public transport systems: Lessons for institutional planning. Transportation Research Part A: Policy and Practice, 42(3), pp. 445-454. DOI: 10.1016/j.tra.2008.01.006

Scheurer, J., Curtis, C. \& Porta, S. (2011) Spatial network analysis of public transport systems: Developing a strategic planning tool to assess the congruence of movement and urban structure in Australian cities, pp. 1-52. Paper presented at the 30th Australasian Transport Research Forum (ATRF), 25-27 September, Melbourne, Australia. Typescript.

Sevtsuk, A. \& Mekonnen, M. (2012) Urban Network Analysis Toolbox. International Journal of Geomatics and Spatial Analysis, 22(2), pp. 287-305. DOI: 10.3166/RIG.22.287-305

Sienkiewicz, J. \& Hołyst, J. A. (2005) Statistical analysis of 22 public transport networks in Poland. Physical Review E, 72(4), pp. 1-11. DOI: 10.1103/PhysRevE.72.046127

Stanilov, K. (2007) The post-socialist city urban form and space transformations in central and eastern Europe after socialism. Dordrecht, Springer Verlag.

Stead, D., de Jong, M. \& Reinholde, I. (2008) Urban transport policy transfer in central and eastern Europe. DisP - The Planning Review, 44(172), pp. 62-73. DOI: 10.1080/02513625.2008.10557003

Stefanovska, J. \& Koželj, J. (2012) Urban planning and transitional development issues: The case of Skopje, Macedonia. Urbani izziv, 23(1), pp. 91-100. DOI: 10.5379/urbani-izziv-en-2012-23-01-002

Stoleriu, O. (2008) Evoluția uman-geografică şi urbanistică a oraşului laşi în perioada postbelică. Iași, Terra Nostra.

Strano, E., Cardillo, A., lacoviello, A., Latora, V., Messora, R., Porta, S. \& Scellato, S. (2007) Street centrality vs. commerce and service locations in cities: A kernel density correlation case study in Bologna, Italy. Available at: http://arxiv.org/ftp/physics/papers/0701/0701111.pdf (accessed 12 March 2015).

Sykora, L. \& Bouzarovski, S. (2012) Multiple transformations: Conceptualising the post-communist urban transition. Urban Studies, 49(1), pp. 43-60. DOl: 10.1177/0042098010397402

Tosics, I. (2005) City development in central and eastern Europe since 1990: The impacts of internal forces. In: Hamilton, F. E. l., Dimitrovska Andrews, K. \& Pichler-Milanović, N. (eds.) Transformation of cities in central and eastern Europe: Towards globalization, pp. 44-78. New York, United Nations University Press.

Tsenkova, S. (2014) The housing policy nexus and people's responses to housing challenges in post-communist cities. Urbani izziv, 25(2), pp. 90-106. DOI: 10.5379/urbani-izziv-en-2014-25-02-002

Tsietsi Monare, P., Kotze, N. \& Morton McKay, T. (2014) A second wave of gentrification: The case of Parkhurst, Johannesburg, South Africa. Urbani izziv, 25(supplement), pp. S108-S121.

DOI: 10.5379/urbani-izziv-en-2014-25-supplement-008
Verovšek, S., Juvančič, M. \& Zupančič, T. (2013) Using visual language to represent interdisciplinary content in urban development: Selected findings. Urbani izziv, 24(2), pp. 144-155. DOI: 10.5379/urbani-izziv-en-2013-24-02-006

Viton, P. A. (1997) Technical efficiency in multi-mode bus transit: A production frontier analysis. Transportation Research Part B: Methodological, 31(1), pp. 23-39. DOI: 10.1016/S0191-2615(96)00019-7

Von Ferber, C., Holovatch, T., Holovatch, Y. \& Palchykov, V. (2009) Public transport networks: Empirical analysis and modeling. The European Physical Journal B - Condensed Matter and Complex Systems, 68(2), pp. 261-275. DOI: 10.1140/epjb/e2009-00090-x

Von Hirschhausen, C. \& Cullmann, A. (2010) A nonparametric efficiency analysis of German public transport companies. Transportation Research Part E: Logistics and Transportation Review, 46(3), pp. 436-445. DOI: 10.1016/j.tre.2009.11.005

Young, C. \& Kaczmarek, S. (2008) The socialist past and post-socialist urban identity in central and eastern Europe: The case of Lodz, Poland. European Urban and Regional Studies, 15(1), pp. 53-70. DOI: $10.1177 / 0969776407081275$

Yu, B., Yang, Z., Cheng, C. \& Liu, C. (2005) Optimizing bus transit network with parallel ant colony algorithm. Proceedings of the Eastern Asia Society for Transportation Studies, 5(1), pp. 374-389. 